\title{
Putting parental overprotection into a family systems context: Relations of overprotective parenting with perceived coparenting and adolescent anxiety
}

\author{
Stijn Van Petegem ${ }^{1,2,4}$, Gillian Albert Sznitman ${ }^{3}$, Joëlle Darwiche ${ }^{3}$, \& Grégoire Zimmermann ${ }^{3}$ \\ ${ }^{1}$ Université Libre de Bruxelles, Brussels, Belgium \\ ${ }^{2}$ F.R.S.-FNRS Research Associate, Belgium \\ ${ }^{3}$ FAmily and DevelOpment Research Center (FADO), University of Lausanne, Switzerland \\ ${ }^{4}$ Contact: stijn.van.petegem@ulb.be
}

Acknowledgments. The authors would like to thank the adolescents and parents who kindly accepted to participate in the study, as well as the master thesis students and research assistants who helped in the data collection and data input. The data analyzed during the current study are deposited in the FORS repository (https://forsbase.unil.ch/), and are available upon request. This research was supported by two grants from the Swiss National Science Foundation (FNS n ${ }^{\circ}$. 10001C_179455 and FNS n $.10014 / 156155)$.

This article may not exactly replicate the final version published in the journal. The final version is in press in Family Process.

The exact reference is: Van Petegem, S., Albert Sznitman, G., Darwiche, J., \& Zimmermann, G. (2021). Putting parental overprotection into a family systems context: Relations of overprotective parenting with perceived coparenting and adolescent anxiety. Family Process. doi: 10.1111/famp.12709 


\begin{abstract}
Previous research offers evidence for how overprotective parenting is related to psychosocial maladjustment among adolescents, and documents the parent-related and childrelated antecedents of overprotective parenting. Using a family systems perspective, the present study aimed at extending this knowledge by looking into contextual determinants of overprotective parenting. More specifically, the goal of this study was to examine associations between adolescents' perceptions of the coparental relationship (i.e., the way parental figures relate to each other in their role as parents) and overprotective parenting, which in turn was expected to relate to more adolescent anxiety symptoms. A sample of 174 Swiss adolescents $\left(M_{\mathrm{age}}=16.99\right.$ years, $73 \%$ girls $)$ completed questionnaires assessing their perceptions of the coparental relationship (in terms of cooperation, conflict, and triangulation), overprotective parenting, and symptoms of anxiety. Analyses indicated that triangulation, in particular, was uniquely related to higher levels of overprotective parenting, which in turn was associated with more anxiety symptoms among adolescents. These results provide evidence for the importance of considering the larger family systems context for understanding the dynamics involved in overprotective parenting. Theoretical and clinical implications of these findings are discussed.
\end{abstract}

KEYWORDS: overprotection, coparenting, anxiety, triangulation, adolescence, parenting 


\section{Introduction}

During the last decade, the phenomenon of overprotective parenting has been the object of considerable scientific scrutiny. Studies conducted among adolescents and young adults indicate that overprotective parenting may have detrimental consequences, as it may put youth at risk for developing a host of psychosocial difficulties, including social anxiety (Spokas \& Heimberg, 2009), more depressive symptoms (Schiffrin et al., 2014), and more internalizing and externalizing problems (Van Petegem et al., 2020). In addition, research on the antecedents of overprotective parenting has identified a number of parent characteristics (e.g., parental separation anxiety, Brenning, Soenens, Van Petegem, \& Kins, 2017; parental neuroticism, Coplan, Reichel, \& Rowan, 2009) and child characteristics (e.g., an inhibited temperament, Coplan et al., 2009; perceived child vulnerability due to chronic illness, Hullmann et al., 2010) that may serve as determinants of overprotective parenting. Thus, past work has mostly considered overprotective parenting as a phenomenon that occurs within the parent-child dyad (and the mother-child dyad, in particular; e.g., Brussoni \& Olsen, 2013; Wu et al., 2020). This is potentially problematic, as such a restricted focus on either child or parent factors may reinforce an implicit rhetoric where either the child or the parent (and the mother, in particular) is to blame for the child's psychosocial and developmental difficulties (Bristow, 2014; Garey \& Arendell, 2001; Welsh, 2020). This can be overcome by focusing on potential contextual factors, which are generally overlooked in the literature on parental overprotection. Drawing upon family systems theory (Cox \& Paley, 2003), we aimed to test whether characteristics of the coparental relationship, which involves the way parental figures relate to each other in their role as parents (McHale \& Lindahl, 2011), are associated with overprotective parenting during adolescence, which in turn was expected to relate to more adolescent anxiety. Such a focus on the coparenting 
relationship is not only important for gaining insight into its potential benefits for children's and adolescents' development, but also may help to overcome the view that child-rearing is the sole responsibility of the mother (Frascarolo et al., 2016).

\section{Overprotective Parenting during Adolescence}

Parental overprotection refers to parents' provision of protection that is excessive, considering the child's developmental level (Holmbeck et al., 2002; Thomasgard, Metz, Edelbrock, \& Shonkoff, 1995). Particularly during adolescence and young adulthood, developmental periods characterized by children's increasing strive for independence and selfreliance, there may be a higher risk for parents to protect their offspring in ways that do not meet their developmental needs (Guttman \& Eccles, 2007). During adolescence, parental overprotection may take many forms, including parents' tendency to solve adolescents' problems without help being requested, an excessive preoccupation with adolescents' health and safety, and a tendency to warn the adolescent about every potential danger in their environment (e.g., Brenning et al., 2017; Omer, Satran \& Driter, 2016). Although often well-intentioned, overprotection may backfire as it is hypothesized to interfere with a child's development of resilience and coping skills, potentially contributing to anxiety and other mental health problems, such as depression, disordered eating, and behavior problems ( (Parker, 1983; Taborelli et al., 2013; Zimmer-Gembeck \& Skinner, 2016). In that respect, a considerable body of research confirms that parental overprotection is an important risk factor for psychosocial difficulties, including internalizing and externalizing problems (Van Petegem, Antonietti, Eira Nunes, Kins, \& Soenens, 2020), academic difficulties (Schiffrin \& Liss, 2017), and anxiety symptoms in particular (McLeod, Wood, \& Weisz, 2007). For instance, in a longitudinal study, Spokas and Heimberg (2009) found that recollections of overprotective parenting during childhood relates to 
increases in social anxiety among students when they entered their first year at university. Similarly, LeMoyne and Buchanan (2011) found that overprotective parenting relates to lowered psychological well-being, to a higher likelihood of having a prescription of medication for anxiety and depression, and to a higher likelihood of non-prescribed consumption of pain medication.

Further, past research has also yielded insights into the potential determinants of overprotective parenting. Specifically, previous research identified a number of factors related to the child, mostly involving (parental perceptions of) child vulnerability, such as mental health problems (e.g., anxiety disorders; Hudson \& Rapee, 2001), chronic pain (Anno et al., 2015), or perceived vulnerability due to paediatric conditions (Hullmann et al., 2010). Similarly, specific temperamental factors can also elicit overprotective parenting strategies. For instance, in a longitudinal study among parents of 2 to 4-year-olds, Rubin, Nelson, Hastings, and Asendorpf (1999) found that parents who rated their child as shy and inhibited were more likely to constrain their child's independence in order to avoid psychological or physical risk two years later. Furthermore, previous research identified a number of parent factors that are associated with a greater use of overprotective parenting strategies, such as parental anxiety (Segrin et al., 2013) and neuroticism (Coplan et al., 2009). For instance, in a study among mothers of young adults, Brenning et al. (2017) found that a maternal anxious attachment style was related to more maternal separation anxiety, which in turn was associated with more overprotective parenting and a tendency to experience the child's home-leaving as a negative event. Further, in another study, it was found that children of a parent with a clinical diagnosis of anxiety disorder more often perceived that parent as overprotective, as compared to children from a control sample (Lindhout et al., 2006). However, while factors specific to the parent and the child provide a 
certain understanding of the determinants of overprotective parenting, it is necessary to consider contextual sources of stress and support in which the parent-child relationship is embedded in order to gain a more comprehensive view (Bornstein, 2016; Lerner et al., 2018). A focus on family contextual determinants may help to put the phenomenon of overprotective parenting into perspective through the consideration of the larger family context in which such behaviors occur. Drawing upon family systems perspectives (e.g., Bowen, 1978; Cox \& Paley, 1997, 2003; Minuchin, 1974), we argue for the importance of considering the coparental relationship as a contextual determinant for the understanding as to why some parents engage in overprotective parenting.

\section{The Coparental Context of Adolescent Development}

According to family systems perspectives (e.g., Cox \& Paley, 2003; Minuchin, 1985), the family can be conceived of as a dynamic system, composed of multiple subsystems, such as the parent-child subsystem and the coparental subsystem. Coparenting refers to the coordination between any two (or more) adults that share the responsibility for the upbringing of a child (McHale, Negrini, \& Sirotkin, 2019). Previous research shows that coparenting dynamics help to explain why interparental conflict may affect the parent-child relationship and children's adjustment (Bonds \& Gondoli, 2007; Teubert \& Pinquart, 2010). More generally, family system theorists stress the importance of considering coparenting dynamics for understanding how the family contributes to child development (e.g., McHale \& Irace, 2011). Herein, we expected that coparental triangulation, in particular, would be linked to more overprotective parenting, which in turn would relate to more adolescent anxiety.

In the literature, the term triangulation is used in somewhat different ways, but it essentially refers to the process of avoiding or diverting parental conflicts through the 
involvement of the child in these conflicts (Grych, 2002). This may take several forms, such as the formation of cross-generational coalitions (i.e., an alliance between one parent and the child against another parent) or the detouring of the conflict by focusing on problems exhibited by the child (Grych, 2002; Minuchin, Baker, Rosman, Liebman, Milman, \& Todd, 1975; Teubert \& Pinquart, 2010). Typically, triangulating the child is forwarded as a strategy to avoid facing the potential tension or underlying conflict that exists within the parental relationship (Bowen, 1978; Kerig, 1995; Minuchin, 1974). By diverting attention onto the child's difficulties or problems, the parental subsystem is temporarily relieved of the underlying tension and stress existing within the subsystem (Bowen, 1978; Charles, 2001; Parker, 1983). Thus, by becoming overly involved with the child, parents submerge their conflict and dissolve the stress, anxiety, or conflict that exists between them (Minuchin et al., 1978). In other words, overprotective parenting may represent a direct behavioural expression of the underlying triangulation dynamic that operates within the family. Similarly, cross-generational coalitions may also bring about overinvolvement and enmeshment between the allied parent and the child (Grych, 2002). As the child becomes part of an alliance with one parent against the other parent, interpersonal boundaries may become violated, engendering overprotective and invasive parenting practices (Afifi, 2003; Bell, Bell, \& Nakata, 2001). In this case as well, the child becomes involved in the parental conflict, which allows the family system to have the tension deflected and diffused within the system (Dumont, 2019; Kerr \& Bowen, 1988). As the child is brought in between the parents, the stress and tension within the system is reduced in the short run.

However, triangulating the child through the use of overprotective practices is problematic in the long term, as the family system continues to need the child to maintain its homeostasis (Bell et al., 2001; Kerig, 1995; Minuchin et al., 1978). In addition, these triadic 
interaction patterns imply boundary violations as the child must negotiate between parents and manage conflicting loyalties (Amato \& Afifi, 2006; Margolin et al., 2001). This is particularly problematic during the transitional phase of adolescence, where the principal developmental tasks (e.g., identity formation, demands for independence, orientation towards peers) necessitate a rebalancing of the family system and a (re-)negotiation of the rules and roles, thus challenging the entire system (Bowen, 1978; Grych, 2002; Minuchin, 1975). Triangulation may thus be experienced as particularly interfering and overbearing during this developmental phase, and may hamper adolescents' healthy development. As far as we are aware, however, no studies have explicitly examined whether triangulation is associated with overprotective parenting during adolescence, and whether this in turn is associated with adolescents' maladjustment (cf. Favez \& Frascarolo, 2013). Thereby, we focused on adolescent anxiety as a specific indicator of adolescent maladjustment, as theoretical accounts stress that dysfunctional coparenting and overprotective parenting contributes to the development of anxiety in particular (Majdandzic, de Vente, Feinberg, Aktar \& Bögels, 2012; McLeod et al., 2007).

\section{The Present Study}

The overall objective of the current investigation is to put the phenomenon of overprotective parenting into a larger context, by exploring whether specific coparenting dynamics are linked to parents' engagement in overprotective parenting, and whether overprotection, in turn, is linked to higher levels of adolescent anxiety. We thereby made use of adolescents' perceptions of coparenting and overprotective parenting, as it has been argued that their perceptions and interpretations ultimately matter most for understanding how the family contributes to their development (e.g., Hendriks, Van der Giessen, Stams, \& Overbeek, 2018; Kerig, 1995). The first goal was to examine whether coparental triangulation uniquely related to 
more perceived overprotective parenting, thereby controlling for coparental cooperation (i.e., the degree to which there is open communication, trust and mutual loyalty and respect regarding child-rearing issues) and conflict (i.e., the extent to which parents argue and fight with regards to the child's upbringing; Feinberg, 2003; Teubert \& Pinquart, 2010). The second goal was to test a spillover hypothesis (Erel \& Burman, 1995), that is, we examined whether coparental triangulation related to more overprotective parenting, which, in turn, was hypothesized to be associated with more anxiety symptoms.

\section{Method}

\section{Sample and Procedure}

Our sample consisted of 174 adolescents, living in the French-speaking part of Switzerland. Participants ranged in age between 16 and 19 years $(M=16.99, S D=.60)$. The sample is composed of somewhat more girls (73\%) than boys. Further, the majority of our participants (79\%) reported living with both biological parents, whereas $19 \%$ of the participants' parents were separated, and $2 \%$ reported another family constellation. The data were taken from

a larger ongoing longitudinal study. At wave 1, participating adolescents were in $9^{\text {th }}$ grade and were recruited through public schools, situated in both urban and rural regions of the Canton Vaud. The present data were taken from wave 5 (which was 2.5 years after wave 1). Participants who had agreed to participate in the longitudinal study were sent paper-and-pencil questionnaires at home. We included all participating adolescents who had completed the questionnaires of interest for the present study. Through an informed consent, participants were informed about the confidential treatment of their data and the voluntary nature of their participation, which is in compliance with the ethical standards of the Swiss Society of Psychology (SSP).

\section{Measures}


Participants completed French versions of the questionnaires. A validated French version of the coparenting questionnaire was already available (Zimmermann et al., 2020). The other questionnaires were translated following the recommendations of the International Test Commission (Hambleton, 2001).

Perceived coparenting. We measured adolescents' perceptions of coparenting using the Coparenting Inventory for Parents and Adolescents (CI-PA; Teubert \& Pinquart, 2011), which assesses the coparenting dimensions of triangulation, cooperation, and conflict. Specifically, adolescents reported on their perceptions of the coparental relationship at the dyadic level (4 items for each dimension, totalling 12 items: e.g., "My parents agree on whether I did something wrong or not”, reverse-coded, for perceived dyadic conflict), and their perceptions of each parents' contribution to the coparental relationship (5 items for cooperation, 4 items for conflict, 4 items for triangulation, totalling 13 items for each parental figure; e.g., "My mother speaks about my father as a good person", for perceived maternal contribution to coparental cooperation; e.g., "My father uses me as leverage in his arguments with my mother", for perceived paternal contribution to triangulation). Items were rated on a Likert-type scale, ranging 1 (Not at all true) to 5 (Completely true). Previous studies offered evidence for the reliability and validity of this measure (e.g., Teubert \& Pinquart, 2011; Zimmermann et al., 2020). The internal consistencies of the different subscales ranged between .77 and .93 (see Table 1).

Perceived overprotective parenting. Adolescents reported on their perceptions of overprotective parenting using a shortened version of the Multidimensional Overprotective Parenting Scale (MOPS; Kins \& Soenens, 2013). As in previous research (e.g., Brenning et al., 2017), we wanted to assess six components of overprotective parenting (i.e., premature problem solving, anxious rearing, infantilization, emotional hyperactivation, privacy invasion, and general 
perceptions of overprotection). The full version of the MOPS consists of 5 items for each component, totalling 30 items. A shortened version was derived using data from a non-published data set composed of 581 adolescents (59\% girls, age range $=14-19$ years). Specifically, we performed an exploratory factor analysis on the items of each component, and we selected the two highest-loading items for each component, resulting in a 12-item shortened version of the MOPS. This version had a good reliability $(\alpha=.87)$, correlated strongly with the full 30-item version $(r=.96, p<.001)$, and related to relevant variables in ways that were highly similar to the 30-item version (e.g., perceived autonomy-supportive parenting, $r_{12 \text { item }}=-.47, p<.001$, vs. $r_{30 \text { item }}=-.47, p<.001$, parental responsiveness, $r_{12 \text { item }}=-.22, p<.001$, vs. $r_{30 \text { item }}=-.19, p<.001$, perceived controlling parenting, $r_{12 \text { item }}=.49, p<.001$, vs. $r_{30 \text { item }}=.48, p<.001$, adolescent selfesteem, $r_{12 \text { item }}=-.12, p<.01$, vs. $\left.r_{30 \text { item }}=-.11, p<.01\right)$. Example items are "My parents often intervene in things that I could actually solve myself" and "My parents show me the possible risks in everything I do". Participants indicated the degree to which they agreed with each statement, using a scale ranging from 1 (Completely disagree) to 5 (Completely agree). In the present study sample, this 12 -item version was reliable $(\alpha=.89)$.

Adolescent anxiety. Adolescents reported upon their symptoms of anxiety, making use of the Generalized Anxiety subscale of the Screen for Child Anxiety Related Emotional Disorders (SCARED; Birmaher et al., 1997). Participants rated the 9 items of this subscale (e.g., "I worry about things working out for me") based on the severity of symptoms for the past 3 months on a 3-point scale, ranging from 0 (Not true or hardly ever true) to 2 (Very true or often true). The SCARED is an often-used and well-validated questionnaire (e.g., Birmaher, Brent, Chiappetta, Bridge, Monga, \& Baugher, 1999), and was found to be reliable in our sample $(\alpha=.85)$. 


\section{Data Analysis}

As preliminary analyses, we first inspected means, standard deviations, and correlations between the variables of interest. In addition, we performed a MANCOVA to test for differences in our study variables in terms of sex, age, and family structure. Then, we examined the unique associations between overprotective parenting and the coparenting dimensions of triangulation, cooperation, and conflict (cf. the first research question). This was done through three regression analyses, focusing separately on adolescents' perceptions of coparenting at the dyadic level, and on their perceptions of mothers' and fathers' contribution to the coparenting relationship. In a next step, we estimated a structural equation model, where triangulation predicted overprotective parenting, which in turn would predict adolescent anxiety (cf. the second research question). We modelled triangulation as a latent variable, using the three triangulation subscales as indicators (adolescents' perceptions of triangulation at the dyadic level, and their perceptions of fathers' and mothers' contribution to triangulation). Overprotective parenting and adolescent anxiety were also modelled as latent variables, each represented by three separate parcels that were created through a random selection of items of the respective scales (Little, Cunningham, Shahar, \& Widaman, 2002). We used robust ML estimation (MLR) to deal with non-normality observed in some of our variables. We evaluated model fit on the basis of a combined consideration of the comparative fit index (CFI), standardized root-mean-square residual (SRMR) and the root-meansquare error of approximation (RMSEA). A cut-off of .90 for CFI, .08 for RMSEA, and .10 for SRMR indicate a reasonable fit, whereas a CFI higher than .95, RMSEA below .06 and SRMR lower than .08 would indicate a good-fitting model (Hu \& Bentler, 1999). We performed all analyses in R 3.5.3 (R Development Core Team, 2016).

\section{Results}




\section{Preliminary Analyses}

Means, standard deviations, and correlations are presented in Table 1. Perceived overprotective parenting correlated significantly with all coparental dimensions (except with perceived paternal contribution to coparental cooperation), with higher scores on overprotective parenting being strongly associated with more perceived triangulation, and moderately associated with more perceived coparental conflict and less perceived coparental cooperation. The mutual relations between the coparenting dimensions were generally significant, except for the associations of perceived paternal contribution to coparental conflict with perceived paternal contribution to coparental cooperation and with perceived maternal contribution to coparental conflict and cooperation. The triangulation dimensions generally related positively to the conflict dimensions and negatively to the cooperation dimensions, whereas the conflict dimensions were generally negatively associated with the cooperation dimensions. Finally, higher scores on adolescent anxiety related to significantly more perceived overprotective parenting, more perceived triangulation (for each of the three subscales), and more perceived paternal contribution to coparental conflict.

The MANCOVA, testing for differences in terms of sex, age, and family structure, indicated no significant multivariate effects for $\operatorname{sex}[F(11,160)=1.34, p=.21]$ or age $[F(11$, $160)=0.68, p=.75]$. The multivariate effect for family structure was significant $[F(11,160)=$ $3.77, p<.001]$. Univariate analyses indicated significant differences in terms of dyadic cooperation $\left[F(1,170)=29.53, p<.001, M_{\text {two-parent }}=4.24\right.$ vs. $\left.M_{\text {other }}=3.46\right]$, maternal cooperation $\left[F(1,170)=20.04, p<.001, M_{\mathrm{two}-\text { parent }}=4.09\right.$ vs. $\left.M_{\mathrm{other}}=3.38\right]$, paternal cooperation $\left[F(1,170)=21.17, p<.001, M_{\text {two-parent }}=4.10\right.$ vs. $\left.M_{\text {other }}=3.38\right]$, dyadic conflict $\left[F(1,170)=19.55, p<.001, M_{\mathrm{two}-\text { parent }}=2.06\right.$ vs. $\left.M_{\mathrm{other}}=2.69\right]$, dyadic triangulation 
$\left[F(1,170)=5.23, p=.02, M_{\mathrm{two} \text {-parent }}=2.02\right.$ vs. $\left.M_{\mathrm{other}}=2.44\right]$, and maternal triangulation

$\left[F(1,170)=4.12, p=.04, M_{\text {two-parent }}=2.14\right.$ vs. $\left.M_{\text {other }}=2.58\right]$. Given these results, we controlled for family structure throughout our main analyses.

\section{Main Analyses}

We first tested for the unique associations between perceived overprotective parenting and the coparenting dimensions of cooperation, conflict, and triangulation, through three linear regression analyses. The first regression analysis focused on coparenting at the dyadic level. The results are presented in Table 2, and indicated that higher levels of perceived triangulation related uniquely to more perceived overprotective parenting. Dyadic cooperation and conflict were not uniquely associated with overprotection. Results are similar when focusing on adolescents' perceptions of mothers' contribution to the coparental relationship. As can be seen in Table 2, associations for maternal cooperation and conflict were non-significant, whereas higher levels of perceived maternal triangulation related uniquely to more overprotective parenting. Results regarding adolescents' perceptions of fathers' contribution to the coparental relationship indicate no significant unique association between perceived paternal cooperation and overprotective parenting. However, for adolescents' perceptions of fathers' contribution to the coparental relationship, it was found that both perceived coparental conflict and triangulation uniquely related to more parental overprotection (see Table 2) ${ }^{1}$.

Then, we estimated a structural model to examine whether perceived triangulation predicted more perceived overprotective parenting, which in turn would predict more adolescent anxiety. We first estimated the measurement model, which yielded a good fit $\left[\chi^{2}(24)=36.43\right.$, $p=.05, \mathrm{CFI}=.98, \mathrm{RMSEA}=.06, \mathrm{SRMR}=.05]$. Then, we estimated the structural equation model linking coparental triangulation to adolescent anxiety through overprotective parenting. 
The model fitted the data well $\left[\chi^{2}(31)=43.75, p=.05, \mathrm{CFI}=.98, \mathrm{RMSEA}=.05, \mathrm{SRMR}=.06\right]$. Results are depicted in Figure 1, and indicate that triangulation significantly predicted higher levels of overprotective parenting, which in turn predicted more adolescent anxiety. In addition, adding a direct path from triangulation to anxiety did not ameliorate the fit significantly $\left[\Delta \chi^{2}(1)=1.79, p=.18, \Delta \mathrm{CFI}=.001\right]$. Moreover, the indirect effect of triangulation on adolescent anxiety through overprotective parenting was significant $(b=.15, p=.005)$.

As an ancillary analysis, we examined whether family structure moderated the relations depicted in Figure 1, using multigroup comparison analyses. First, we examined measurement equivalence, by comparing a model with all factor loadings freely estimated with a model where the factor loadings were constrained to be equal across the two groups. The multigroup comparison provided evidence for measurement equivalence $\left[\Delta \chi^{2}(6)=3.01, p=.81\right.$, $\Delta \mathrm{CFI}=.003]$. Then, we tested for structural equivalence by comparing an unconstrained model (where the two structural paths were estimated freely) with a constrained model (with these paths set equal across groups). These analyses suggest that the structural paths presented in Figure 1 are not significantly different for adolescents living with their two biological parents vs. adolescents from other family constellations $\left[\Delta \chi^{2}(2)=5.35, p=.07, \Delta \mathrm{CFI}=.004\right]$.

\section{Discussion}

Since a decade or so, there is a striking increase in attention to the phenomenon of overprotective parenting, both in the scientific and the popular literature (e.g., Glass \& Tabatsky, 2014). Previous research efforts documented the implications of overprotective parenting for children's and adolescents' development, as well as the parent-related and child-related antecedents of overprotective parenting (e.g., Brenning et al., 2017). However, models describing determinants of parenting (e.g., Bornstein, 2016) underscore the importance of also 
looking into contextual factors for explaining why parents rely upon certain parenting practices. Herein, we aimed to put the phenomenon of overprotective parenting into a family systems context, in order to better understand the family dynamics that are associated with parental overprotection. As our results show, perceived triangulation, in particular, strongly related to more overprotective parenting, which in turn predicted more anxiety symptoms among adolescents.

The present findings underscore the importance of understanding the phenomenon of overprotective parenting, as it may appear as the symptom of a more fundamental problem in the family system (Dumont, 2019). Indeed, it seems that parents' overprotection also may serve a purpose within the system: by triangulating the child, underlying conflicts and tensions may be diffused within the system (Kerig, 1995; Kerr \& Bowen, 1988). However, especially during adolescence, a developmental phase necessitating the system to find a new balance, this may be experienced as overbearing and may put adolescents' development at risk, potentially bringing about anxiety symptoms and other types of psychopathology (see also Dumont, 2019; Minuchin et al., 1975; Parker, 1983). Thus, these findings shed light on the broader family patterns associated with overprotective parenting, and offer insight into the precise dynamics of how difficulties within the family system may be linked to adolescents' anxiety symptoms (Majdandzic et al., 2012).

These results are important from a clinical and societal point of view as well. As divorce rates are elevated in our contemporary society (e.g., about $20 \%$ in the present sample), there is an increased risk for children to "feel caught between" the parents, where the child feels like having to side with one parent, hence becoming involved in the parents' conflicts (e.g., Afifi, 2003; Buchanan, Maccoby, \& Dornbusch, 1991). In line with this, our preliminary analyses indicated 
that adolescents from separated families perceived higher levels of triangulation, as compared to adolescents living with their two biological parents. These dysfunctional patterns may "spill over" and impact the adolescent's development, if left unaddressed or managed ineffectively (Larson \& Almeida, 1999; Stroud, Meyers, Wilson, \& Durbin, 2015). Of course, it should be noted that such dynamics are not limited to youth from divorced families: research suggests that children with conflicting parents (who do not divorce) may even be worse off, as they continue to be confronted with these difficulties, sometimes even into adulthood (Amato \& Afifi, 2006). Future research, therefore, could focus specifically on similarities and differences in these dynamics among families where adolescents live together with their two biological parents vs. adolescents from separated families and other family constellations.

Finally, these findings are particularly relevant for clinicians working with adolescents and young adults. The transition to adulthood is often challenging and potentially anxietyprovoking for youth, especially in a changing society where pathways to adulthood become increasingly diversified and individualized due to globalization and socio-economic changes (e.g., Côté, 2018; Shanahan, 2000). When young people consult professionals as they struggle during this transitional phase, it may be worthwhile "zooming out" in order to gain a more contextualized and fuller picture: potentially, the adolescents' anxiety symptoms serve an underlying function that can only be understood by gaining more insight into the family system's functioning. These difficulties, then, can be addressed either in individual sessions (see e.g., Dumont, 2019) or through family interventions (e.g., Minuchin, 2012; Titelman, 2014). In addition, although beyond the scope of this paper, it may be important to further zoom out and consider macro-contextual factors as well, as socio-economic changes (e.g., growing economic inequality, societal pressures about how to raise children) may also push parents to become 
overly involved (e.g., Doepke \& Zilibotti, 2019; Lukianoff \& Haidt, 2019).

A number of limitations should be acknowledged. First, the cross-sectional data preclude drawing any conclusions regarding directionality. In the present study, adolescents' anxiety symptoms are modelled as an outcome variable; however, anxiety symptoms may also trigger parental worries, which may elicit overprotective parenting and negative coparenting (Majdandzic et al., 2012) ${ }^{1}$. Longitudinal research is needed to examine directionality of effects. Moreover, we solely relied upon adolescent perceptions. This is a strength, as past research on coparenting rarely relies upon adolescent perceptions (Zimmermann et al., 2020) and as past research indicates that their perceptions and interpretations often matter most for understanding how (co)parenting is associated to their development (e.g., Hendriks et al., 2018). However, recent research on overprotective parenting indicated that it is important to consider multiple perspectives (in terms of both congruence and incongruence) for understanding the dynamics involved in overprotective parenting (Van Petegem et al., 2020). Future research therefore should rely upon a multi-informant design. Multi-informant information also allows for the consideration of single-informant bias. For instance, anxious adolescents may be biased in their perceptions and interpretations of parental behaviors (e.g., Waite et al., 2015). Reliance upon multi-informant information, observational information (e.g., Wuyts et al., 2018) or a vignettemethodology (e.g., Van Petegem et al., 2019) may help to take potential bias into account that is due to the single-informant nature of the data. In addition, qualitative research could yield a more in-depth understanding of how overprotective parenting represents a behavioural expression of underlying triangulation dynamics, where interpersonal boundaries are potentially violated (Afifi, 2003).

Further, our assessment of overprotective parenting did not differentiate between mothers 
and fathers. Although past research offers no evidence for differences in the implications of maternal vs. paternal overprotection (e.g., Overbeek, Ten Have, Vollebergh, \& De Graaf, 2007), the present approach could obscure gendered pathways. This may be particularly relevant in the context of the observation that perceived father-driven coparenting conflict was a unique predictor of overprotective parenting, whereas this was not the case for mother-driven conflict. This is fairly surprising, as past research indicates that mother-reported coparenting conflict is particularly predictive of youth psychosocial functioning, whereas this is not so much the case for father-reported coparenting conflict (Riina et al., 2020). Disentangling perceptions of maternal vs. paternal parenting and coparenting seems essential for future research to gain a better understanding of potentially gendered pathways.

In a related way, it is interesting for future research to also focus on links with maternal gatekeeping, which is defined as a set of beliefs and behaviors that may inhibit collaborative efforts between men and women in family work (Allen \& Hawkins, 1999), and which is linked to negative coparenting and lower levels of father involvement (Schoppe-Sullivan, Brown, Cannon, Mangelsdorf, \& Sokolowski, 2008). Potentially, overprotective parenting practices may be a manifestation of gatekeeping dynamics within a family system, and may help to explain gendered differences in overprotective parenting. Finally, it should be noted that our study relied upon a community sample, characterized by relatively low levels of coparenting conflict and triangulation, and high levels of coparenting cooperation. Future research could focus on clinical samples in order to examine the generalizability of the documented associations.

Despite these limitations, the present study offers important insights into the coparental context in which overprotective parenting may arise throughout development. Triangulation, in particular, was found to be associated with more overprotective parenting. Although 
triangulating the adolescent may allow a family system to diffuse tension and conflict within the system, our study suggest that this is problematic as these triangulation dynamics may be experienced as overprotective, hence setting the adolescent at risk for anxiety symptoms. 


\section{Footnotes}

${ }^{1}$ As a set of ancillary tests, we repeated the initial regression analyses, thereby including adolescent anxiety as an additional predictor of overprotective parenting. The unique effects of adolescent anxiety on overprotective parenting were not significant, and the obtained associations between coparenting and overprotection were very similar to the results documented in the paper. 


\section{References}

Afifi, T. D. (2003). 'Feeling caught' in stepfamilies: Managing boundary turbulence through appropriate communication privacy rules. Journal of Social and Personal Relationships, $20,729-755$.

Albert Sznitman, G., Van Petegem, S., \& Zimmermann, G. (2019). Exposing the role of coparenting and parenting for adolescent personal identity processes. Journal of Social and Personal Relationships, 36, 1233-1255.

Allen, S. M., \& Hawkins, A. J. (1999). Maternal gatekeeping: Mothers' beliefs and behaviors that inhibit greater father involvement in family work. Journal of Marriage and the Family, 61, 199-212.

Amato, P., \& Afifi, T. D. (2006). Feeling caught between parents: Adult children's relations with parents and subjective well-being. Journal of Marriage and the Family, 68, 222-235.

Anno, K., Shibata, M., Ninomiya, T., Iwaki, R., Kawata, H., Sawamoto, R., ... \& Hosoi, M. (2015). Paternal and maternal bonding styles in childhood are associated with the prevalence of chronic pain in a general adult population: The Hisayama Study. BMC Psychiatry, 15, 1-8.

Bell, L. G., Bell, D. C., \& Nakata, Y. (2001). Triangulation and adolescent development in the US and Japan. Family Process, 40, 173-186.

Birmaher, B., Brent, D. A., Chiappetta, L., Bridge, J., Monga, S., \& Baugher, M. (1999). Psychometric properties of the Screen for Child Anxiety Related Emotional Disorders (SCARED): A replication study. Journal of the American Academy of Child \& Adolescent Psychiatry, 38, 1230-1236.

Birmaher, B., Khetarpal, S., Brent, D., Cully, M., Balach, L., Kaufman, J., \& Neer, S. M. (1997). 
The Screen for Child Anxiety Related Emotional Disorders (SCARED): Scale construction and psychometric characteristics. Journal of the American Academy of Child \& Adolescent Psychiatry, 36, 545-553.

Bonds, D. D., \& Gondoli, D. M. (2007). Examining the process by which marital adjustment affects maternal warmth: The role of coparenting support as a mediator. Journal of Family Psychology, 21, 288-296.

Bornstein, M. H. (2016). Determinants of parenting. In D. Cicchetti (Ed.), Developmental psychopathology: Risk, resilience, and intervention (pp. 1-91). Hoboken, NJ: John Wiley \& Sons Inc.

Bowen, M. (1978). Family therapy in clinical practice. New York, NY: Jason Aronson.

Brenning, K., Soenens, B., Van Petegem, S., \& Kins, E. (2017). Searching for the roots of overprotective parenting in emerging adulthood: Investigating the link with parental attachment representations using an Actor Partner Interdependence Model (APIM). Journal of Child and Family Studies, 26, 2299-2310.

Bristow, J. (2014). The double bind of parenting culture: Helicopter parents and cotton wool kids. In E. Lee, J. Bristow, C. Faircloth, \& J. Macvarish (Eds.), Parenting culture studies (pp. 200-215). Palgrave Macmillan, London.

Brussoni, M., \& Olsen, L. L. (2013). The perils of overprotective parenting: Fathers' perspectives explored. Child: Care, Health and Development, 39, 237-245.

Buchanan, C. M., Maccoby, E. E., \& Dornbusch, S. M. (1991). Caught between parents: Adolescents' experience in divorced homes. Child Development, 62, 1008-1029.

Charles, R. (2001). Is there any empirical support for Bowen's concept of differentiation of self, triangulation, and fusion? American Journal of Family Therapy, 29, 279-292. 
Coplan, R. J., Reichel, M., \& Rowan, K. (2009). Exploring the associations between maternal personality, child temperament, and parenting: A focus on emotions. Personality and individual differences, 46(2), 241-246.

Côté, J. E. (2018). Youth development in identity societies: Paradoxes of purpose. New York, NY: Routledge.

Cox, M. J., \& Paley, B. (1997). Families as systems. Annual Review of Psychology, 48, 243-267.

Cox, M. J., \& Paley, B. (2003). Understanding families as systems. Current Directions in Psychological Science, 12, 193-196.

Doepke, M., \& Zilibotti, F. (2019). Love, money, and parenting: How economics explains the way we raise our kids. Princeton University Press.

Dumont, D. E. (2019). Facing adulthood: Helicopter parenting as a function of the family projection process. Journal of College Student Psychotherapy, 1-14.

Erel, O., \& Burman, B. (1995). Interrelatedness of marital relations and parent-child relations: A meta-analytic review. Psychological Bulletin, 118, 108-132.

Favez, N., \& Frascarolo, F. (2013). Le coparentage: composants, implications et thérapie. Devenir, 25, 73-92.

Feinberg, M. E. (2003). The internal structure and ecological context of coparenting: A framework for research and intervention. Parenting: Science and Practice, 3, 95-131.

Frascarolo, F., Feinberg, M., Albert Sznitman, G., \& Favez, N. (2016). Professional gatekeeping toward fathers: A powerful influence on family and child development. Perspectives in Infant Mental Health, 1-7. 
Garey, A. I., \& Arendell, T. (2001). Children, work, and family. In R. Hertz \& N. L. Marshall (Eds.), Working families: The transformation of the American home (pp. 293-303). Berkeley : University of California Press.

Glass, G. S., \& Tabatsky, D. (2014). The Overparenting epidemic: Why helicopter parenting is bad for your kids... and dangerous for you, too!. New York, NY: Skyhorse Publishing.

Grych, J. H. (2002). Marital relationships and parenting. In M. H. Bornstein (Ed.), Handbook of parenting: Volume 4 social conditions and applied parenting (pp. 203-226). Mahwah, NJ: Lawrence Erlbaum Associates.

Gutman, L. M., \& Eccles, J. S. (2007). Stage-environment fit during adolescence: Trajectories of family relations and adolescent outcomes. Developmental Psychology, 43, 522-537.

Hambleton, R. K. (2001). The next generation of the ITC Test Translation and Adaptation Guidelines. European Journal of Psychological Assessment, 17, 164-172.

Hendriks, A. M., Van der Giessen, D., Stams, G. J. J. M., \& Overbeek, G. (2018). The association between parent-reported and observed parenting: A multi-level meta-analysis. Psychological Assessment, 30, 621.

Holmbeck, G. N., Johnson, S. Z., Wills, K. E., McKernon, W., Rose, B., Erklin, S., \& Kemper, T. (2002). Observed and perceived parental overprotection in relation to psychosocial adjustment in preadolescents with a physical disability: The mediational role of behavioral autonomy. Journal of Consulting and Clinical Psychology, 70, 96-110.

Hu, L. T., \& Bentler, P. M. (1999). Cutoff criteria for fit indexes in covariance structure analysis: Conventional criteria versus new alternatives. Structural Equation Modeling, 6, 1-55.

Hudson, J. L., \& Rapee, R. M. (2001). Parent-child interactions and anxiety disorders: An observational study. Behaviour Research and Therapy, 39, 1411-1427. 
Hullmann, S. E., Wolfe-Christensen, C., Ryan, J. L., Fedele, D. A., Rambo, P. L., Chaney, J. M., \& Mullins, L. L. (2010). Parental overprotection, perceived child vulnerability, and parenting stress: a cross-illness comparison. Journal of Clinical Psychology in Medical Settings, 17, 357-365.

Kerig, P. K. (1995). Triangles in the family circle: Effects of family structure on marriage, parenting, and child adjustment. Journal of Family Psychology, 9, 28-43.

Kerr, M. E., \& Bowen, M. (1988). Family evaluation: An approach based on Bowen theory. New York, NY: W. W. Norton \& Company.

Kins, E., \& Soenens, B. (2013). Generation me and its helicopter parents. Paper presented at the 16th European Conference on Developmental Psychology, Lausanne, Switzerland.

Larson, R. W., \& Almeida, D. M. (1999). Emotional transmission in the daily lives of families: A new paradigm for studying family process. Journal of Marriage and the Family, 61, 5-20.

LeMoyne, T., \& Buchanan, T. (2011). Does "hovering” matter? Helicopter parenting and its effect on well-being. Sociological Spectrum, 31, 399-418.

Lerner, R. M., Brindis, C. D., Batanova, M., \& Blum, R. W. (2018). Adolescent health development: A relational developmental systems perspective. In N. Halfon, C. B. Forrest, R. M. Lerner, \& E. M. Faustman (Eds.), Handbook of life course health development (pp. 109-121). Springer.

Lindhout, I., Markus, M., Hoogendijk, T., Borst, S., Maingay, R., Spinhoven, P., ... \& Boer, F. (2006). Childrearing style of anxiety-disordered parents. Child Psychiatry and Human Development, 37, 89-102.

Little, T. D., Cunningham, W. A., Shahar, G., \& Widaman, K. F. (2002). To parcel or not to parcel: Exploring the question, weighing the merits. Structural Equation Modeling, 9, 151-173. 
Lukianoff, G., \& Haidt, J. (2019). The coddling of the American mind: How good intentions and bad ideas are setting up a generation for failure. Penguin Books.

Majdandžić, M., de Vente, W., Feinberg, M. E., Aktar, E., \& Bögels, S. M. (2012). Bidirectional associations between coparenting relations and family member anxiety: A review and conceptual model. Clinical Child and Family Psychology Review, 15, 28-42.

Margolin, G., Gordis, E. B., \& John, R. S. (2001). Coparenting: A link between marital conflict and parenting in two-parent families. Journal of Family Psychology, 15, 3-21.

McHale, J. P., \& Irace, K. (2011). Coparenting in diverse family systems. In J. P. McHale \& K. M. Lindahl (Eds.), Coparenting: A conceptual and clinical examination of family systems (pp. 15-37). Washington, DC: American Psychological Association.

McHale, J. P., \& Lindahl, K. M. (2011). Coparenting: A conceptual and clinical examination of family systems. Washington, DC: American Psychological Association.

McHale, J. P., Negrini, L., \& Sirotkin, Y. (2019). Coparenting. In B. H. Fiese, M. Celano, K. Deater-Deckard, E. N. Jouriles, \& M. A. Whisman (Eds.), APA handbooks in psychology®. APA handbook of contemporary family psychology: Foundations, methods, and contemporary issues across the lifespan (pp. 483-502). Washington, DC: American Psychological Association.

McLeod, B. D., Wood, J. J., \& Weisz, J. R. (2007). Examining the association between parenting and childhood anxiety: A meta-analysis. Clinical Psychology Review, 27, 155-172.

Minuchin, S. (1974). Families and family therapy. Cambridge, MA: Harvard University Press.

Minuchin, P. (1985). Families and individual development: Provocations from the field of family therapy. Child Development, 56, 289-302.

Minuchin, S. (2012). Families and family therapy by Salvador Minuchin. New York, NY: 
Routledge.

Minuchin, S., Baker, L., Rosman, B. L., Liebman, R., Milman, L., \& Todd, T. C. (1975). A conceptual model of psychosomatic illness in children: Family organization and family therapy. Archives of General Psychiatry, 32, 1031-1038.

Minuchin, S., Rosman, B. L., \& Baker, L. (1978). Psychosomatic families: Anorexia nervosa in context. Oxford, England: Harvard University Press.

Omer, H., Satran, S., \& Driter, O. (2016). Vigilant care: An integrative reformulation regarding parental monitoring. Psychological Review, 123, 291-304.

Overbeek, G., ten Have, M., Vollebergh, W., \& de Graaf, R. (2007). Parental lack of care and overprotection. Social Psychiatry and Psychiatric Epidemiology, 42, 87-93.

Parker, G. (1983). Parental overprotection: A risk factor for psychosocial development. New York, NY: Grune and Stratton.

R Development Core Team. (2016). R: A language and environment for statistical computing. Vienna, Austria: R Foundation for Statistical Computing.

Riina, E. M., Lee, J. K., \& Feinberg, M. E. (2020). Bidirectional associations between youth adjustment and mothers' and fathers' coparenting conflict. Journal of Youth and Adolescence, 49, 1617-1630.

Rubin, K. H., Nelson, L. J., Hastings, P., \& Asendorpf, J. (1999). The transaction between parents' perceptions of their children's shyness and their parenting styles. International Journal of Behavioral Development, 23, 937-957.

Schiffrin, H. H., \& Liss, M. (2017). The effects of helicopter parenting on academic motivation. Journal of Child and Family Studies, 26, 1472-1480. 
Schiffrin, H. H., Liss, M., Miles-McLean, H., Geary, K. A., Erchull, M. J., \& Tashner, T. (2014). Helping or hovering? The effects of helicopter parenting on college students' well-being. Journal of Child and Family Studies, 23, 548-557.

Segrin, C., Woszidlo, A., Givertz, M., \& Montgomery, N. (2013). Parent and child traits associated with overparenting. Journal of Social and Clinical Psychology, 32, 569-595.

Schoppe-Sullivan, S. J., Brown, G. L., Cannon, E. A., Mangelsdorf, S. C., \& Sokolowski, M. S. (2008). Maternal gatekeeping, coparenting quality, and fathering behavior in families with infants. Journal of Family Psychology, 22, 389-398.

Spokas, M., \& Heimberg, R. G. (2009). Overprotective parenting, social anxiety, and external locus of control: Cross-sectional and longitudinal relationships. Cognitive therapy and research, 33, 543-551.

Shanahan, M. J. (2000). Pathways to adulthood in changing societies: Variability and mechanisms in life course perspective. Annual Review of Sociology, 26, 667-692.

Stroud, C. B., Meyers, K. M., Wilson, S., \& Durbin, C. E. (2015). Marital quality spillover and young children's adjustment: Evidence for dyadic and triadic parenting as mechanisms. Journal of Clinical Child \& Adolescent Psychology, 44, 800-813.

Taborelli, E., Krug, I., Karwautz, A., Wagner, G., Haidvogl, M., Fernandez-Aranda, F., ... \& Treasure, J. L. (2013). Maternal anxiety, overprotection and anxious personality as risk factors for eating disorder: A sister pair study. Cognitive Therapy and Research, 37, 820828.

Teubert, D., \& Pinquart, M. (2010). The association between coparenting and child adjustment: A meta-analysis. Parenting: Science and Practice, 10, 286-307.

Teubert, D., \& Pinquart, M. (2011). The Coparenting Inventory for Parents and Adolescents (CI- 
PA): Reliability and validity. European Journal of Psychological Assessment, 27, 206-215.

Titelman, P. (2014). Clinical applications of Bowen family systems theory. New York, NY: Routledge.

Thomasgard, M., Metz, W. P., Edelbrock, C., \& Shonkoff, J. P. (1995). Parent-child relationship disorders: I. Parental overprotection and the development of the parent protection scale. Journal of Developmental and Behavioral Pediatrics, 16, 244-250.

Van Petegem, S., Antonietti, J. P., Eira Nunes, C., Kins, E., \& Soenens, B. (2020). The relationship between maternal overprotection, adolescent internalizing and externalizing problems, and psychological need frustration: A multi-informant study using response surface analysis. Journal of Youth and Adolescence, 49, 162-177.

Van Petegem, S., Zimmer-Gembeck, M., Baudat, S., Soenens, B., Vansteenkiste, M., \& Zimmermann, G. (2019). Adolescents' responses to parental regulation: The role of communication style and self-determination. Journal of Applied Developmental Psychology, 65, 101073.

Waite, P., Codd, J., \& Creswell, C. (2015). Interpretation of ambiguity: Differences between children and adolescents with and without an anxiety disorder. Journal of Affective Disorders, 188, 194-201.

Welsh, T. (2020). Meta-helicopter parenting: Ambivalence in a neoliberal world. In A. S. LaChance (Ed.), The Maternal Tug: Ambivalence, identity, and agency. Bradford: Demeter Press.

Wu, Q., Zhang, J., \& Slesnick, N. (2020). Intergenerational transmission of maternal overprotection and child anxiety in substance-using families. Journal of Anxiety Disorders, $73,102236$. 
Wuyts, D., Soenens, B., Vansteenkiste, M., \& Van Petegem, S. (2018). The role of observed autonomy support, reciprocity, and need satisfaction in adolescent disclosure about friends. Journal of Adolescence, 65, 141-154.

Zimmer-Gembeck, M. J., \& Skinner, E. A. (2016). The development of coping: Implications for psychopathology and resilience. In D. Cicchetti (Ed.), Developmental psychopathology: Risk, resilience, and intervention (pp. 485-545). Hoboken, NJ: John Wiley \& Sons Inc.

Zimmermann, G., Antonietti, J.-P., Albert Sznitman, G., Van Petegem, S., \& Darwiche, J. (2020). The French version of the coparenting inventory for parents and adolescents (CI-PA): Psychometric properties and a cluster analytic approach. Journal of Family Studies. doi: https://doi.org/10.1080/13229400.2020.1749714 


\section{Tables}

Table 1

Means, Standard Deviations, Reliabilities and Correlations Among the Variables of Interest

\begin{tabular}{|c|c|c|c|c|c|c|c|c|c|c|c|}
\hline & 1. & 2. & 3. & 4. & 5. & 6. & 7. & 8. & 9. & 10. & 11. \\
\hline \multicolumn{12}{|l|}{$\begin{array}{l}\text { 1. Overprotective } \\
\text { parenting }\end{array}$} \\
\hline 2. Triangulation dyad & $.44 * *$ & & & & & & & & & & \\
\hline 3. Triangulation mother & $.47 * *$ & $.63 * *$ & & & & & & & & & \\
\hline 4. Triangulation father & $.39 * *$ & $.60 * *$ & $.71 * *$ & & & & & & & & \\
\hline 5. Conflict dyad & $.25 * *$ & $.48 * *$ & $.41 * *$ & $.41^{* *}$ & & & & & & & \\
\hline 6. Conflict mother & $.23 * *$ & $.36^{* *}$ & $.49 * *$ & $.37 * *$ & $.37 * *$ & & & & & & \\
\hline 7. Conflict father & $.33 * *$ & $.23 * *$ & $.18^{*}$ & $.21 * *$ & $.23 * *$ & -.14 & & & & & \\
\hline 8. Cooperation dyad & $-.21 * *$ & $-.47 * *$ & $-.43 * *$ & $-.33 * *$ & $-.75^{* *}$ & $-.28 * *$ & $-.15^{*}$ & & & & \\
\hline 9. Cooperation mother & $-.17 *$ & $-.34 * *$ & $-.37 * *$ & $-.30 * *$ & $-.56 * *$ & $-.25 * *$ & -.04 & $.70 * *$ & & & \\
\hline 10. Cooperation father & -.05 & $-.28 * *$ & $-.28 * *$ & $-.27 * *$ & $-.53 * *$ & $-.25 * *$ & -.01 & $.67 * *$ & $.75^{* *}$ & & \\
\hline 11. Anxiety & $.22 * *$ & $.25^{* *}$ & $.17 *$ & $.16^{*}$ & .09 & -.03 & $.19 *$ & -.04 & -.01 & .08 & \\
\hline Mean & 2.08 & 2.10 & 2.23 & 1.94 & 2.19 & 2.53 & 2.41 & 4.08 & 3.94 & 3.95 & 1.03 \\
\hline$S D$ & 0.74 & 1.01 & 1.19 & 0.94 & 0.80 & 1.03 & 0.94 & 0.84 & 0.90 & 0.89 & 0.54 \\
\hline$\alpha$ & .89 & .86 & .93 & .89 & .80 & .81 & .77 & .84 & .83 & .82 & .85 \\
\hline
\end{tabular}

Note. $* p<.05 . * * p<.01$. 
Table 2

Linear Regressions of Perceived Coparenting Predicting Overprotective Parenting

\begin{tabular}{|c|c|c|c|c|c|c|c|c|c|c|c|c|}
\hline \multirow{2}{*}{$\begin{array}{l}\text { Level of focus } \\
\text { (coparenting) }\end{array}$} & \multicolumn{4}{|c|}{ Dyad } & \multicolumn{4}{|c|}{ Mother } & \multicolumn{4}{|c|}{ Father } \\
\hline & $b$ & $S E$ & $\beta$ & $p$ & $b$ & $S E$ & $\beta$ & $p$ & $b$ & $S E$ & $\beta$ & $p$ \\
\hline $\begin{array}{l}\text { Family } \\
\text { structure }^{1}\end{array}$ & .26 & .13 & .14 & .05 & .23 & .13 & .13 & .07 & .07 & .13 & .04 & .59 \\
\hline Cooperation & .00 & .09 & .00 & .99 & -.03 & .06 & -.04 & .60 & .03 & .06 & .03 & .65 \\
\hline Conflict & .08 & .10 & .09 & .42 & -.01 & .06 & -.01 & .87 & .20 & .05 & .26 & $<.001$ \\
\hline Triangulation & .31 & .06 & .43 & $<.001$ & .30 & .05 & .48 & $<.001$ & .27 & .06 & .34 & $<.001$ \\
\hline $\mathrm{R}^{2}$ & .22 & & & & .24 & & & & .22 & & & \\
\hline
\end{tabular}




\section{Figures}

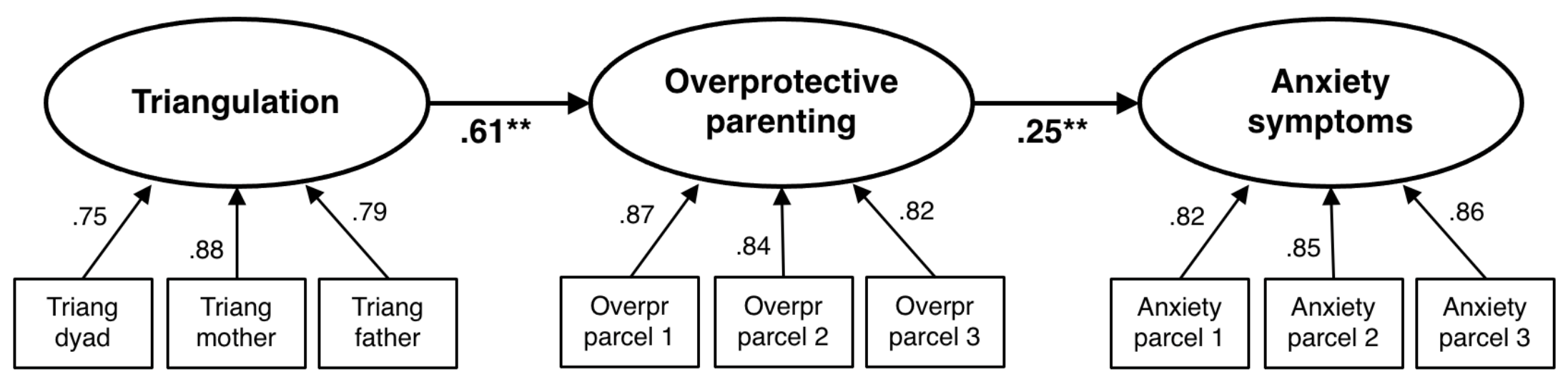

Figure 1. Structural equation model depicting the associations between triangulation, overprotective parenting, and adolescent anxiety. ${ }^{*} p<.05{ }^{* *} p<.01$. 